\title{
New Insights into the Nucleolar Localization of a Plant RNA Virus-Encoded Protein That Acts in Both RNA Packaging and RNA Silencing Suppression: Involvement of Importins Alpha and Relevance for Viral Infection
}

\author{
Miryam Pérez-Cañamás and Carmen Hernández ${ }^{\dagger}$ \\ Instituto de Biología Molecular y Celular de Plantas (Consejo Superior de Investigaciones Científicas-Universidad Politécnica de \\ Valencia). Ciudad Politécnica de la Innovación, Ed. 8E. Camino de Vera s/n, 46022 Valencia, Spain
}

Accepted 17 May 2018.

\begin{abstract}
Despite the fact that replication of plus-strand RNA viruses takes place in the cytoplasm of host cells, different proteins encoded by these infectious agents have been shown to localize in the nucleus, with high accumulation at the nucleolus. In most cases, the molecular determinants or biological significance of such subcellular localization remains elusive. Recently, we reported that protein $\mathrm{p37}$ encoded by Pelargonium line pattern virus (family Tombusviridae) acts in both RNA packaging and RNA silencing suppression. Consistently with these functions, p37 was detected in the cytoplasm of plant cells, although it was also present in the nucleus and, particularly, in the nucleolus. Here, we searched for further insights into factors influencing p37 nucleolar localization and into its potential relevance for viral infection. Besides mapping the protein region containing the nucleolar localization signal, we have found that p37 interacts with distinct members of the importin alpha familymain cellular transporters for nucleo-cytoplasmic traffic of proteins-and that these interactions are crucial for nucleolar targeting of p37. Impairment of p37 nucleolar localization through downregulation of importin alpha expression resulted in a reduction of viral accumulation, suggesting that sorting of the protein to the major subnuclear compartment is advantageous for the infection process.
\end{abstract}

Viruses, as obligate intracellular parasites, must employ many cellular resources to establish productive infections. Despite the fact that replication of plus strand (+) RNA viruses (either from plants or animals) occurs in the cytoplasm of host cells, distinct proteins encoded by these infectious agents have been reported to enter the nucleus, some of them showing high accumulation at the nucleolus (Hiscox 2007; Salvetti and Greco 2014; Taliansky et al. 2010). In most cases, the biological

${ }^{\dagger}$ Corresponding author; Carmen Hernández;

E-mail: cahernan@ibmcp.upv.es

Funding: This work was supported by Ministerio de Economía y Competitividad (MINECO, Spain) Fundo Europeu de Desenvolvimento Regional (FEDER) (grant BFU2015-70261 to C. Hernández). M. PérezCañamás was the recipient of a predoctoral contract from MINECOFEDER.

*The $\boldsymbol{e}$-Xtra logo stands for "electronic extra" and indicates that one supplementary table is published online.

@ 2018 The American Phytopathological Society meaning of such subcellular localization remains obscure. Moreover, information on one or both the structural determinants and host factors that are involved in the nuclear or nucleolar targeting of the corresponding protein is frequently scarce.

Current knowledge indicates that nucleo-cytoplasmatic trafficking of most proteins is an active process that takes place through the nuclear pore complex (NPC) and usually follows the classical import pathway. In this pathway, proteins destined for transport to the nucleus contain a so-called nuclear localization signal (NLS) within their primary sequence that is recognized by a heterodimeric nuclear-cytoplasmic shuttling receptor consisting of importin alpha and importin beta. The importin alpha component plays a central role as an adaptor molecule mediating interaction between the cargo and importin beta, which, in turn, facilitates passage of the cargo-importin alpha transient complex through the central transporter of NPC (McPherson et al. 2015). Once inside the nucleus, some proteins remain in the nucleoplasm, whereas others associate to subnuclear bodies, the nucleolus being the most prominent one with a typical size that can reach up to $8 \mu \mathrm{m}$. Nucleolus has a well-known role in rRNA transcription, processing, and ribosome biogenesis but, in the last years, it has been involved in a growing number of additional functions, including cell-cycle regulation, gene silencing, senescence, stress responses, and biogenesis of multiple kinds of ribonucleoprotein (RNP) particles (Boisvert et al. 2007; Olson and Dundr 2015; Shaw 2015). The localization of proteins to the nucleolus has not been shown to involve active transport mechanisms and is typically dictated by interaction with nucleolar core components, yet, in most of the cases, depends on the presence of one or more nucleolar localization signals (NoLSs) (Carmo-Fonseca et al. 2000; Emmott and Hiscox, 2009; Martin et al. 2015).

Pelargonium line pattern virus (PLPV) is a (+) RNA virus that belongs to a new genus-Pelarspovirus - within the broad family Tombusviridae (Castaño and Hernández 2005; Castaño et al. 2009; Scheets et al. 2015). Its monopartite genome encodes five proteins, one of which, with a molecular weight of $37 \mathrm{kDa}(\mathrm{p} 37)$, has been reported to act as both coat protein (CP) and viral RNA silencing suppressor (VSR) (Pérez-Cañamás and Hernández 2015). Analysis of the subcellular distribution of a green fluorescent protein (GFP)-tagged p37 transiently expressed in Nicotiana benthamiana leaves showed that p37 localizes in the cytoplasm of plant cells (Pérez-Cañamás and Hernández 2015). However, though no NLS (nor NoLS) could be predicted in the protein by in silico approaches, GFP-tagged p37 was also found inside the nucleus, with preponderant 
accumulation at the nucleolus. The biological implications of the nuclear/nucleolar targeting of p37 are, so far, uncertain, as it apparently does not significantly influence either of the two identified functions of the protein, encapsidation, and RNA silencing suppression (Pérez-Cañamás and Hernández 2015). Such targeting could thus be related to unknown roles of the protein during the infection process or, alternatively, with some host defense mechanism aimed to one or both reduce VSR impact on host endogenous pathways and restrict viral infection by precluding encapsidation and antiviral silencing inhibition. Indeed, recent results suggest that the VSR activity of PLPV must be tightly regulated during infection, as the virus is a very efficient target of RNA silencing (Pérez-Cañamás et al. 2017).

Here, we have intended to get further insights into the molecular determinants for nuclear/nucleolar localization of PLPV p37. First, we have studied the subcellular distribution of untagged p37 in the context of a real viral infection. Second, we have attempted to delimit the boundaries of the structural motif directing p37 to nucleolus. Third, we have explored, through bimolecular fluorescence complementation (BiFC) and RNA interference (RNAi) assays, the potential involvement of importins alpha in nuclear/nucleolar targeting of p37. As such participation has been confirmed, we have tackled whether downregulation of importins alpha, leading to impairment of the nuclear/nucleolar targeting of p37, has any effect on virus accumulation. Based on the obtained results, presumptive roles of the subcellular partitioning of PLPV p37 are further discussed.

\section{RESULTS}

PLPV p37 produced during viral infection shows cytoplasmic and nuclear/nucleolar distribution paralleling that found for transiently expressed GFP-tagged p37.

The pattern of subcellular distribution of a protein may be affected by multiple factors and can undergo substantial alterations in response to environmental conditions (Görner et al. 1998; Henke et al. 2011; Noirot et al. 2014). Moreover, incorporation of a tag into a protein may have a significant impact in actual behavior of the protein (Bouia et al. 2001; Brothers et al. 2003; Ledent et al. 1997). As mentioned above, previous work showed that transiently expressed GFP-tagged p37 localized in the cytoplasm and the nucleus/nucleolus of plant cells (Pérez-Cañamás and Hernández 2015). We wondered whether this intracellular distribution could be extrapolated seamlessly to the unfused protein and, moreover, to that produced in the course of a real infection. To answer this question, systemic leaves from PLPV-infected $N$. benthamina plants were used as starting material to obtain cytoplasm- and nucleienriched fractions. For comparison purposes, N. benthamiana leaves were agroinfiltrated with constructs for transient expression of GFP-tagged or untagged p37, and 3 days after infiltration (dai), this plant material was used to prepare the same type of fractions. Western blot analysis of the obtained samples using an antibody against uridine $5^{\prime}$ diphosphate (UDP)glucose pyrophosphorylase (cytoplasmic marker) and histone 3 (H3) (nuclear marker) supported the reliability of the fractionation, since the former protein was detectable in the cytoplasmic fractions but undetectable in the nuclear ones and the opposite was found for the latter (Fig. 1). Analysis of samples prepared from leaves expressing GFP-tagged p37 with a p37specific antibody revealed the presence of the fusion protein in both the cytoplasmic and the nuclear fractions (Fig. 1, left panel), in agreement with the results of confocal microscopy examinations (Pérez-Cañamás and Hernández 2015). Similarly, untagged p37 expressed either transiently through agroinfiltration or during viral infection was distributed between cytoplasmic and nuclear fractions (Fig. 1, central and right panels). These observations further substantiated previous results on the subcellular localization of the p37 and indicated that neither the tag nor the context of viral infection has a significant impact on the distribution of the protein within the cell.

\section{Nucleolar targeting of p37 is directed by a short stretch of $\mathrm{N}$-terminal amino acid residues.}

Though programs for subcellular localization prediction did not recognize any NoLS (nor NLS) in the p37 molecule, previous mutational analysis suggested that one or more nonconventional NoLSs must be present at the N-terminus of the protein and identified several amino acid (aa) residues relevant for the nucleolar localization. Specifically, alanine replacement of either two arginines at positions 15 and 16 or of a tryptophan at position 28 in the GFP-tagged p37 abolished nucleolar localization of the fusion protein (Pérez-Cañamás and Hernández 2015) (Fig. 2A). To corroborate the involvement of the
GFP tagged p37 (transiently expressed)

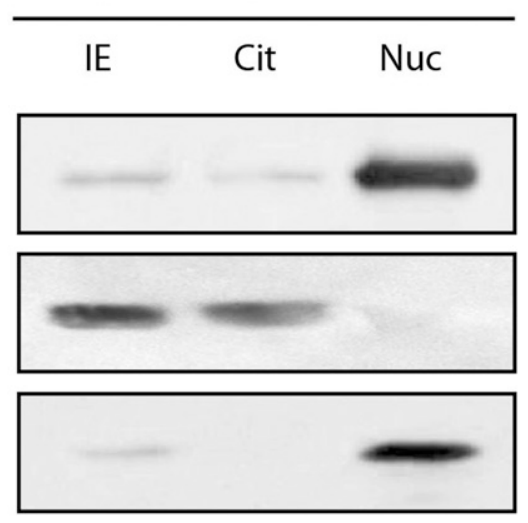

untagged p37 (transiently expressed)

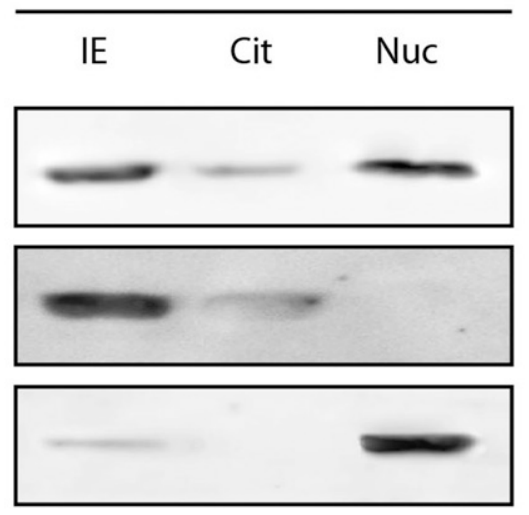

untagged p37 (during PLPV infection)

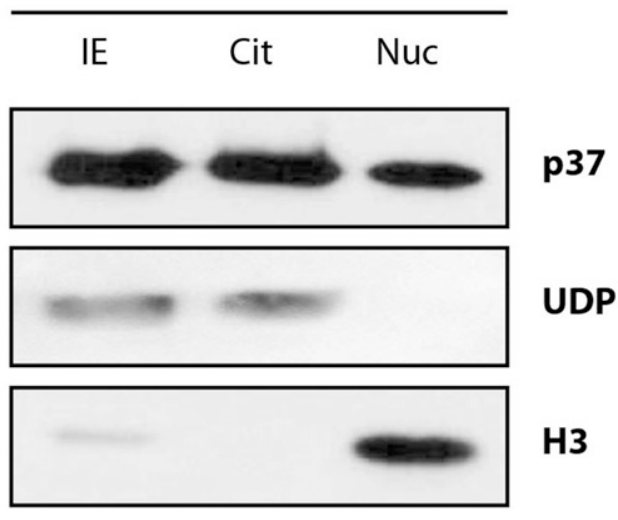

Fig. 1. Analysis of p37 localization through subcellular fractionation and Western blot analysis. Aliquots of input extracts (IE), cytoplasmic fractions (Cit), and nuclear fractions (Nuc) were subjected to sodium dodecyl sulfate-polyacrylamide gel electrophoresis followed by Western blot analysis, using either an antip37 (upper row), anti-UDP glucose pyrophosphorylase (middle row), or anti-H3 (lower row) antibody. Extracts were prepared from Nicotiana benthamiana leaves transiently expressing a green fluorescent protein (GFP)-tagged p37 (left panel) or an untagged p37 (center panel), or from systemic leaves (right panel) of Pelargonium line pattern virus (PLPV)-infected N. benthamiana. Positions of p37, UDP glucose pyrophosphorylase, and H3 are indicated at the right. 
A

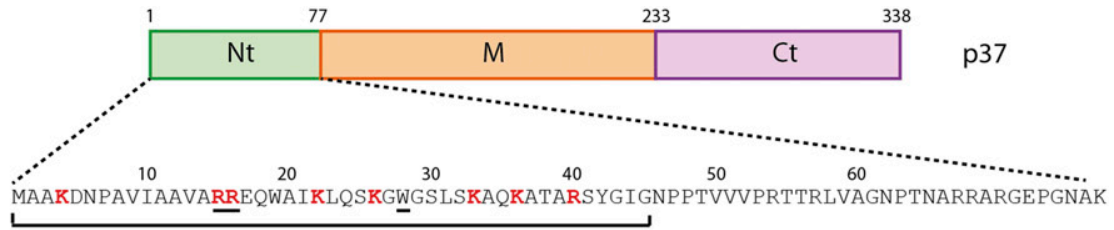

NoLS containing region

B

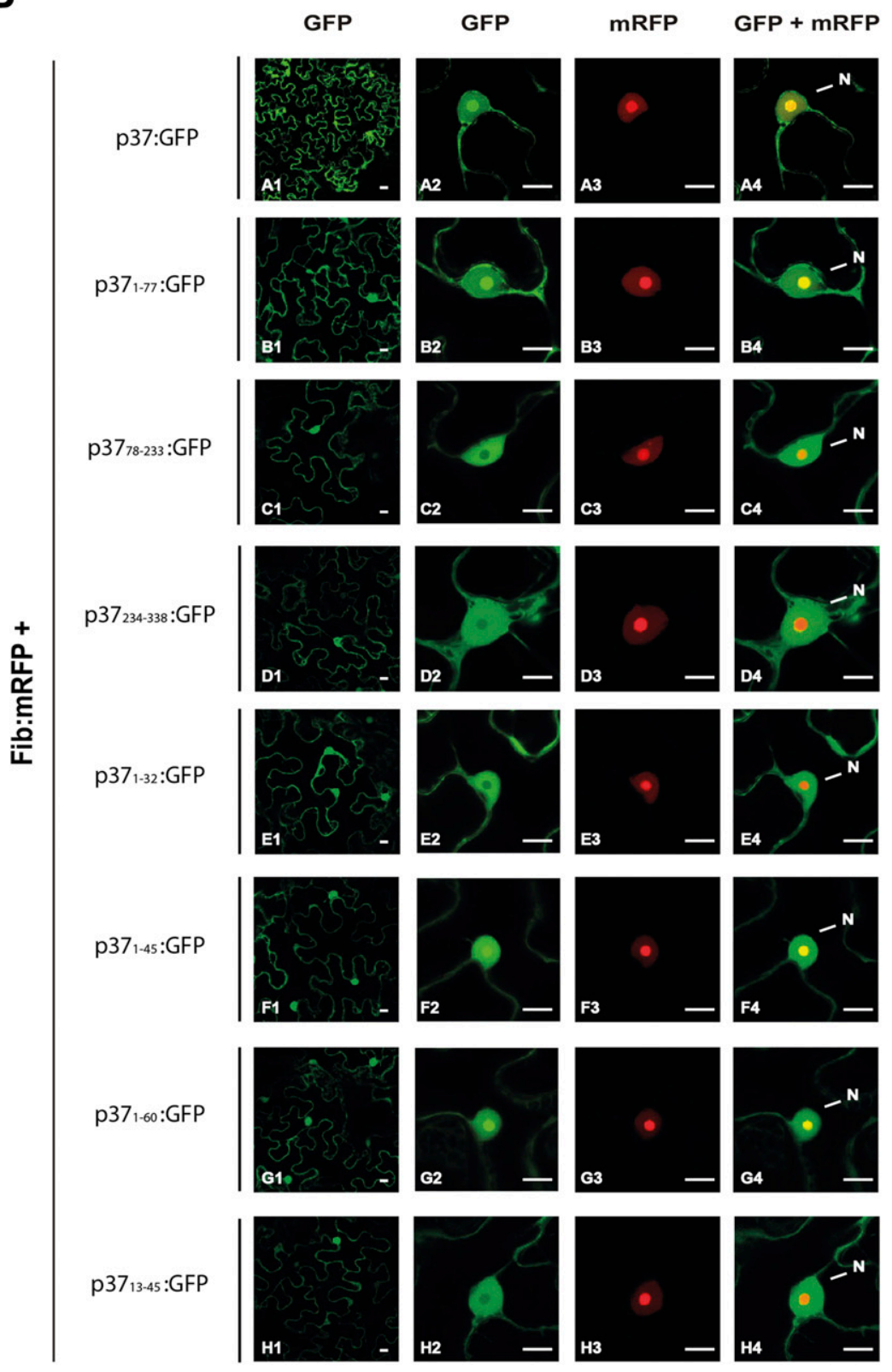

Fig. 2. Subcellular distribution of p37-deletion derivatives with a C-terminal green fluorescent protein (GFP) tag. A, Schematic representation of Pelargonium line pattern virus (PLPV) p37 indicating the boundaries of the $\mathrm{N}$-terminal (Nt), middle (M), and $\mathrm{C}$-terminal $(\mathrm{Ct})$ domains. Amino acid (aa) sequence of the $\mathrm{N}$-terminal domain is detailed at the bottom; the aa stretch that has been determined here as sufficient for nucleolar localization is within a square bracket, and aa residues that were previously shown to be essential for nucleolar localization of a GFP-tagged p37 (Pérez-Cañamás and Hernández 2015) are underlined. B, Confocal microscopy images showing the subcellular distribution of GFP-tagged p37 (p37:GFP) and deletion derivatives (p37 $1-77, \mathrm{p} 37_{78-233}, \mathrm{p} 37_{234-338}, \mathrm{p} 37_{1-}$ ${ }_{60}, \mathrm{p} 37_{1-45}, \mathrm{p} 37_{1-32}$, and $\mathrm{p} 37_{13-45}$ :GFP) transiently expressed in Nicotiana benthamiana cells. The GFP-tagged proteins were expressed along with a monomeric red fluorescent protein (mRFP)-tagged fibrillarin (Fib-mRFP, nucleolar marker). Micrographs of the first column (starting from the left) show a general view of GFP-derived fluorescence in epidermal cells expressing the distinct proteins. The second and third columns show closeup views of GFP- and mRFP-derived fluorescence, respectively, in individual cells, and the fourth column shows merged images of GFP and mRFP signals in such individual cells. The nucleus (N) is marked by an arrow in fourth column panels. The inset scale bar corresponds to $10 \mu \mathrm{m}$ in all panels. 
$\mathrm{N}$-terminal region of p37 in nucleolar targeting and to discard the contribution of other protein segments to localization in nucleolus, the $\mathrm{N}$-terminal (aa 1 to 77 ), middle (aa 78 to 232), and C-terminal (aa 233 to 338 ) domains of p37 were separately fused in frame to GFP. The resulting recombinant proteins were transiently expressed, along with monomeric red fluorescent protein (mRFP)-tagged fibrillarin (used as nucleolar marker) (Kim et al. 2007), in N. benthamiana leaves via agroinfiltration. Assessment of the subcellular distribution of the GFP-tagged proteins through confocal microscopy showed that only that embracing the N-terminal domain retained the nucleolar lo-

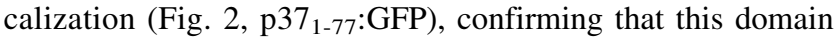
contains one or more signals that direct p37 to nucleoli. To further delimit the p37 region that is required for nucleolar targeting, various deletions were introduced into the $\mathrm{N}$-terminal domain to create a new series of GFP fusion proteins. These proteins included, respectively, aa 1 to 60,1 to 45,1 to 32 , and 13 to 45 of the p37 molecule (Fig. 2). Inspection of the subcellular distribution of the engineered proteins showed that the stretch harboring the most N-terminal 45 aa was sufficient for nucleolar localization (Fig. 2B, p37 $1-45$ :GFP). Additional deletions of $\mathrm{N}$-terminal (p37 $13-45: \mathrm{GFP})$ or C-terminal (p37 $1-32$ : GFP) aa led to nucleolar exclusion (Fig. 2B). Collectively, the results allowed us to delimit the NoLS-containing region of p37 to the first $\mathrm{N}$-terminal 45 aa, which, moreover, was consistent with previous outcomes with p37 mutants (Pérez-Cañamás and Hernández 2015).

\section{PLPV p37 interacts with distinct importins alpha.}

As indicated above, nucleo-cytoplasmatic trafficking of proteins takes place through the NPC and usually follows the classical import pathway in which members of the importin alpha family play a central role. In N. benthamiana, this family is composed of 14 members that can be grouped in three major phylogenetic clusters (I, II, and III), the first of which can be further subdivided into three subclusters (Ia, Ib, Ic) (Fig. 3A). To assess whether p37 importins alpha are able to recognize p37 to mediate its transport to the nucleus and, in turn, the nucleolus, we explored, through BiFC assays, potential interactions between $\mathrm{p} 37$ and representatives of the distinct clusters and subclusters of the importin alpha family. To this end, constructs for transient expression of five different importins alpha (belonging to subclusters Ia, Ib, and Ic, and clusters II and III, respectively) fused to the $\mathrm{N}$ - or $\mathrm{C}$-terminal part of the superyellow fluorescent protein (sYFP) were generated. These constructs were used in proper combinations with others allowing transient expression of p37 fused to the $\mathrm{N}$ - or C-terminal part of sYFP (Pérez-Cañamás and Hernández 2015). $N$. benthamiana cells coexpressing sYFPN-p37 and any of the sYFPC-importin alpha members showed clear sYFP-derived fluorescence, indicating reconstitution of the fluorophore and, thus, demonstrating that $\mathrm{p} 37$ is able to interact with members of the importin alpha family included into distinct clusters and subclusters (Fig. 3B). Similar results were obtained with reverse protein combinations, i.e., when sYFPC-p37 was coexpressed with any of the sYFPN-importin alpha fusion proteins (data not shown). Moreover, control experiments in which the distinct fusion proteins were coexpressed with unfused sYFP halves (Fig. 3B, row F, for example) did not result in any significant fluorescence, reinforcing the validity of detected interactions. Interestingly, in most cases the fluorescence was essentially localized in the nucleus and particularly concentrated at the nucleolus, suggesting that the interaction between the two partners, p37 and importin alpha of any type, mostly either occurs, is maintained, or both in this subnuclear body. The only exception corresponded to the importin alpha representative of clade III, for which the interaction with p37 was detected not only in the nucleus and nucleolus but, also, in the cytoplasm (Fig. 3B, row E). In addition, the latter interaction was apparently weaker than that observed with the remaining importins alpha included in the study, though reconstituted fluorescence was clear when compared with the results of negative controls (Fig. 3B, row $\mathrm{E}$ versus row $\mathrm{F}$ ).

Besides the BiFC approach, a coimmunoprecipitation assay was performed to further corroborate the interaction of $\mathrm{p} 37$ with importin alpha of clade III. To this aim, the importin alpha representative of clade III and also that of subclade Ia, used as positive control, were fused in frame to a histidine (His) tag and were transiently expressed in $N$. benthamiana leaves along with p37. After protein extraction, immunoprecipitates were obtained using an antibody against the His tag. Western blot analysis with the anti-His antibody revealed the presence of importins alpha of clade III and subclade Ia in the corresponding immunoprecipitates, as expected (Fig. 3C, upper panels). Remarkably, p37 was also present in those immunoprecipitates, confirming the interaction between both types of proteins as shown by the BiFC assays (Fig. 3C, lower panels). No p37 was detected when neither importin alpha was included in the input extracts, supporting the reliability of the immunoprecipitation procedure (Fig. 3C). Collectively, the results of this section indicated, on one side, that p37 is able to interact with members of all groups of the importin alpha family, and, on the other, that such interaction takes place mainly at the nucleus and, especially, at the nucleolus. It is worth mentioning that mRFP-tagged importin alpha proteins, at least those corresponding to the representative members of subclades $\mathrm{Ia}$ and $\mathrm{Ib}$ (also annotated as importin alpha 1 and alpha 2, respectively [Fig. 3]), have been shown to have a nuclear localization with high accumulation at the nucleolus (Kanneganti et al. 2007), and thus, the distribution pattern of the interaction of p37 with importins alpha reproduces that of the latter ones.

\section{Downregulation of importins alpha through RNAi severely impairs nucleolar localization of p37.}

In the light of the results from BiFC assays, we wondered whether importins alpha could be one of the key host factors determining localization of p37 at the nucleolus. To answer this question, we downregulated the expression levels of importins alpha using an RNAi approach. More specifically, we designed five binary constructs with expression cassettes that, after delivery via agroinfiltration into plant leaves, would yield hairpin transcripts able to impair expression of importins alpha included in clades and subclades II, III, Ia, Ib, and Ic through RNA silencing. The gene segments for RNAi constructs of each importin alpha clade and subclade were carefully selected from specific gene regions to reasonably ensure silencing of members belonging to a given phylogenetic group or subgroup and not to other groups or subgroups. $N$. benthamiana leaves coinfiltrated with a mixture of Agrobacterium tumefaciens strains transformed with each of these constructs showed reduced accumulation of the distinct importin alpha members, as could be corroborated by semiquantitative reverse transcription-polymerase chain reaction (RT-PCR) assays (Fig. 4A). When the RNAi constructs were assayed separately, reduction in expression levels induced by each RNAi construct was found to be clade-specific, as desired, though some crosstarget silencing was observed for members of subclades within clade I (Fig. 4B), most likely dictated by their high sequence conservation. Despite such cross-reaction, employment of all three subclade constructs was considered useful in the following assays, on one side, because they could reinforce silencing of importins alpha of clade I when combined and, on the other, because they could provide results that should be comparable to each other when used individually.

Analysis of the subcellular distribution of transiently expressed GFP-tagged p37 in plant cells with reduced 
expression of importins alpha of the different clades and subclades showed substantial loss of nucleolar localization (Fig. 4C). Nucleolar localization of p37 reached percentages as low as $28 \%$ when all importins alpha were simultaneously silenced, which contrasted with the total lack of p37 nucleolar exclusion in leaves agroinfiltrated with an empty RNAi vector used as negative control for importin alpha silencing (Fig. 4C). Underlining the specificity of the assay, nucleolar localization of mRFP-tagged fibrillarin was not affected by importin alpha depletion (Fig. 4C; data not shown), in agreement with previous results showing that targeting of fibrillarin to the nucleus or nucleolus was independent of, at least, importins alpha 1 and alpha 2 (Kanneganti et al. 2007). Collectively, the results strongly supported that importins alpha play an essential role in the nucleolar targeting of p37.

Impairment of importin alpha expression correlates with decreased accumulation of PLPV at early stages of infection.

As shown above, depletion of importins alpha negatively affected the nuclear/nucleolar localization of $\mathrm{p} 37$. To assess whether such depletion also had an impact on the progress of

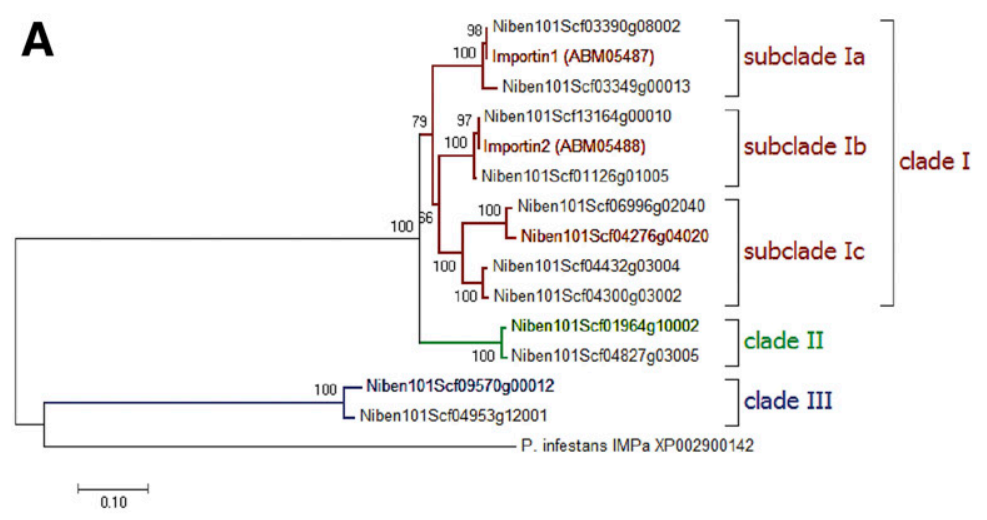

B
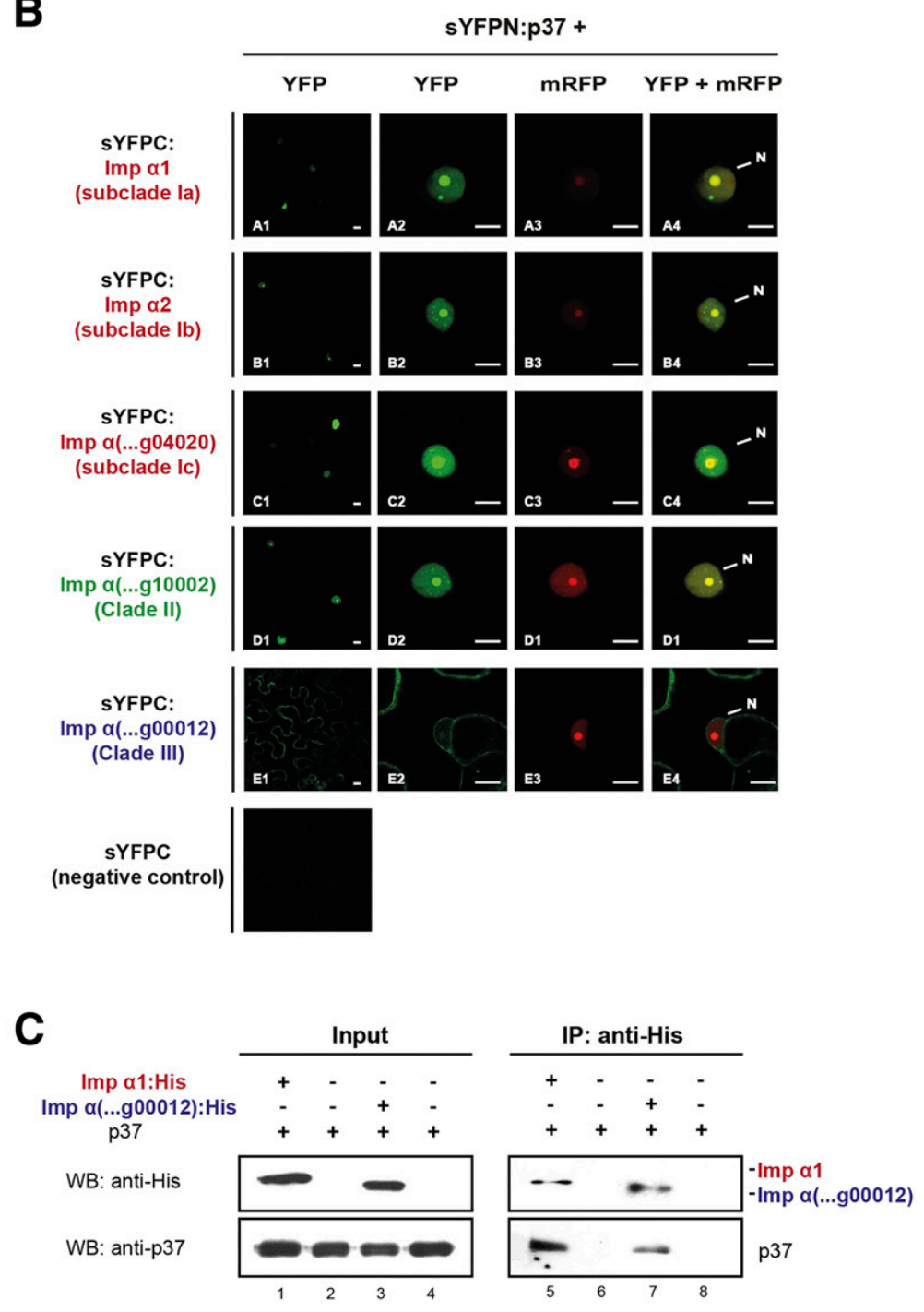
viral infection, the RNAi approach was once more employed to silence importins alpha. The importin alpha-silenced leaves, along with mock-agroinfiltrated controls, were inoculated with PLPV. Leaves were collected at 1, 2, 3, and 7 days postinoculation (dpi) and were subjected to Northern blot analysis to check PLPV accumulation. The results showed a notable decrease in viral titers in the importin alpha-silenced leaves with regard to the nonsilenced controls at early times of infection (Fig. 5A, compare signal intensities in lanes b and $c$ with those of lanes $\mathrm{f}$ and $\mathrm{g}$, respectively). Such decrease was no longer evident at $7 \mathrm{dpi}$, a timepoint in which the virus had apparently reached saturating levels in either sample (Fig. 5A, lanes d and h). Quantitative RT-PCR (RT-qPCR) performed on samples collected at two timepoints, 3 and $7 \mathrm{dpi}$, corroborated, on one side, the efficient importin alpha silencing driven by the RNAi approach (Fig. 5B, right panel), and on the other, the significant reduction of PLPV accumulation in importin alpha-silenced versus nonsilenced leaves at $3 \mathrm{dpi}$ (Fig. 5B, left panel). As could be inferred by the Northern blot analysis, RTqPCR data indicated that differences in viral accumulation were not significant at $7 \mathrm{dpi}$, suggesting that the virus overcomes the detrimental effect caused by importin alpha downregulation at later stages of infection (Fig. 5). We tried to complement the results of the RNAi approach through a Tobacco rattle virus (TRV)-based virus-induced gene silencing (VIGS) assay (Bachan and Dinesh-Kumar 2012). However, TRV infection of $N$. benthamiana plants initiated with a TRV vector either empty or with importin alpha gene fragments, precluded subsequent PLPV infection in one or both local and systemic leaves (data not shown), suggesting that TRV multiplication outcompetes that of PLPV. Though this prevented us from using a VIGS assay to assess the potential relevance of importins alpha in the biological cycle of PLPV, the results of the RNAi approach were clear and showed that impairment of importin alpha expression adversely affects PLPV accumulation. As such impairment hampered nucleolar localization of p37 (Fig. 4), a correlation between the loss of p37 nucleolar targeting and a decrease in PLPV titers could be established.

\section{DISCUSSION}

In this work, we have obtained new and relevant insights into determinants for nucleolar localization of PLPV p37, a viral protein with a dual role as $\mathrm{CP}$ and VSR. In the first place, we have delimited the NoLS-containing region to the most $\mathrm{N}$-terminal 45 aa residues. Systematic analysis of confirmed NoLSs has revealed a great sequence diversity that makes NolSs particularly difficult to predict. Despite such difficulty, some common traits can be seen that are also shared by the p37 NoLS including an N-terminal location and a considerable enrichment in basic aa (Fig. 2) (Martin et al. 2015; Scott et al. 2010). As stated previously (Pérez-Cañamás and Hernández 2015), the NoLS-containing region of $\mathrm{p} 37$ is also involved in other relevant properties of the protein such as the capacity to bind small RNAs, which is essential for its VSR function. In addition, it very likely forms part of the so-called RNA binding domain that has been proposed to directly interact with viral single-stranded RNA for virion formation in related CPs (Rao 2006; Sit and Lommel 2015). These observations emphasize once more the high overlap of motifs involved in different functional traits of p37, as we stressed in a previous study (Pérez-Cañamás and Hernández 2015).

Besides delineating the NoLS-containing region, we have obtained results supporting the idea that subcellular localization of p37 is not affected either by its fusion to a tag or, more importantly, in the context of a real infection. This is not a trivial issue, as cellular compartmentalization of a protein-either viral or cellular-may undergo relevant alterations during the cell cycle or under different environmental conditions, which is all the more the case when an active process of viral infection is ongoing (Alexander and Cilia 2016; Drissi et al. 2013). The presence of other PLPV proteins besides p37, the complex network of interactions that can be established between them and host proteins, and the profound effects that a replicating virus may have on host cellular functions might have resulted in significant discrepancies in the subcelullar localization of a transiently expressed GFP-tagged protein and that produced during a genuine viral infection process, and our results have ruled out that possibility.

We have also shown that p37 is able to interact with different members of the importin alpha family and, moreover, that such interaction most likely dictates the nucleolar localization of the viral product. These observations suggest that the protein has evolved the mechanisms to ensure its nuclear/nucleolar import regardless of changes in the level of a specific type of importin alpha. Such redundancy in the nuclear traffic of viral proteins is not unusual and has been reported previously for proteins encoded by animal, fungi, as well as plant viruses such as the TGB1 of a pomovirus whose nuclear/nuclear localization was affected by knockdown of two distinct importins alpha (Kanneganti et al. 2007; König et al. 2010; Lukhovitskaya et al. 2015; Melen et al. 2003; O’Neill et al. 1995; Smith et al. 1997). In addition, we cannot completely discard the involvement of other nuclear import pathways, besides the classical importin alpha/importin beta pathway, in the nuclear/nucleolar targeting of $\mathrm{p} 37$. Indeed, though the presence of the protein in the

\footnotetext{
Fig. 3. Analysis of potential interactions between p37 and representative members of the importin alpha family through bimolecular fluorescence complementation (BiFC) and coimmunoprecipitation assays. A, A phylogenetic tree of the 14 members of the importin alpha family encoded by Nicotiana benthamiana. Alignments were made using ClustalW and the tree was generated by the neighbor-joining method, using complete deletion treatments with MEGA7. Numbers at branches show the percentage bootstrap support (if $>50 \%$ ) for 1,000 replicates. The scales indicate JTT amino acid distances. Phytophthora infestans importin alpha was used as outgroup. Numbers represent accessions from the Sol Genomics database and GenBank accession numbers. The layout of the tree was essentially identical to that obtained by Lukhovitskaya et al. (2015) with sequences retrieved from Sol Genomics Network, although, in the present case, an updated version of the database has been used for phylogenetic analysis. B, The p37 and importin alpha molecules were tagged at their N-terminus with superyellow fluorescent protein (sYFP) halves (sYFPN and sYFPC) and were transiently coexpressed in $N$. benthamiana leaves to study protein-protein interactions through a BiFC assay. A monomeric red fluorescent protein (mRFP)-tagged fibrillarin (Fib-mRFP), employed as nucleolar marker, was also coexpressed. Confocal laser-scanning microscopy was used for the observation of fluorescence at 3 days after infiltration. For each protein combination, micrographs on the left show a general view of YFP-derived fluorescence in epidermal cells (inset scale bar, $10 \mu \mathrm{m}$ ). The second and third columns show closeup views of YFP- and mRFP-derived fluorescence, respectively, in individual cells. The micrographs in the fourth column show merged images of YFP and mRFP signals in such individual cells (inset scale bar, $10 \mu \mathrm{m}$ ). The nucleus (N) is marked by an arrow in the fourth column panels. A negative control combination (sYFPN:p37 plus sYFPC) is displayed in the bottom row. Equivalent images were obtained with the reverse combinations (YFPC:p37 coexpressed with sYFPN-tagged importins alpha) (data not shown). C, Western blot analysis of protein preparations. Importin alpha molecules of clade III and subclade Ia were fused at their C-terminus with a His-tag and were expressed in $N$. benthamiana leaves either alone or in combination with p37. Input protein extracts (left panel) or immunoprecipitates (IP) (right panel) obtained with anti-His antibody were subjected to Western blot (WB) analysis, using either an anti-His antibody (for detection of importins alpha; upper blots) or an anti-p37 antisera (for detection of p37; lower blots).
} 
nucleolus was strongly reduced by downregulation of importins alpha, a nonnegligible amount of the protein was still evident in the nucleoplasm of cells that showed nucleolar exclusion of $\mathrm{p} 37$ (Fig. 4B), suggesting that mechanisms distinct from those involving importin alpha may contribute somehow to the nuclear sorting of $\mathrm{p} 37$.

The ultimate reasons of the nucleolar (and nuclear, singly or together) targeting of p37 remains elusive, as occurs with other proteins that show this subcellular localization. Previous work showed that it was not strictly required for either the encapsidation or the VSR function of PLPV p37 (Pérez-Cañamás and
Hernández 2015), but here, we have shown that impairment of such localization through importin alpha knockdown negatively affects viral accumulation. Several scenarios can be envisioned to explain these observations. First, it is possible that importin alpha-mediated transport of $\mathrm{p} 37$, the most abundantly produced viral protein during PLPV infection, significantly interferes with the conventional pathway for cytoplasmic-nuclear shuttling of host proteins, thus changing cellular homeostasis to favor the infectious process. Alternatively, p37 confinement in the nucleolus might help to regulate viral protein ratios, an essential issue for virus survival (Castaño et al. 2009). This

A

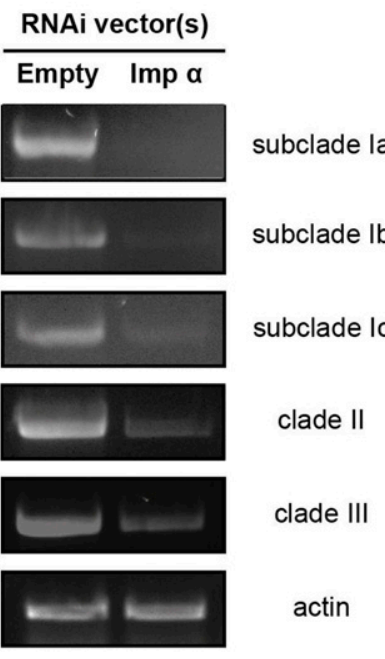

C

RNAiEmpty

lade II

clade III

actin

RNAi-

B

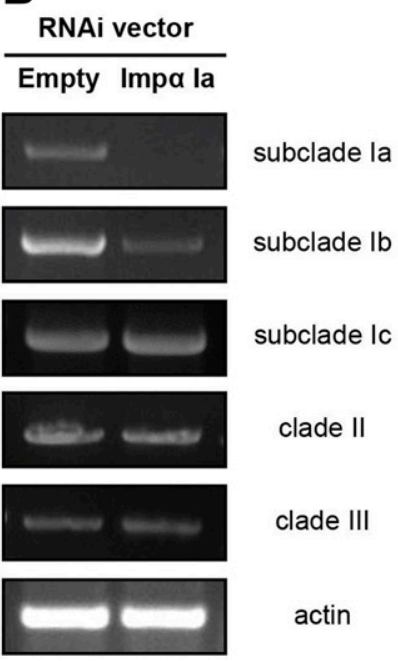

\begin{tabular}{|cc|}
\hline RNAi & Nucleolar localization \\
Empty & $100 \%$ \\
Imp a (subclade la) & $71.8 \%$ \\
Imp a (subclade Ib) & $64.7 \%$ \\
Imp a (subclade Ic) & $81.8 \%$ \\
Imp a (clade II) & $74.5 \%$ \\
Imp a (clade III) & $86.4 \%$ \\
All importins $\alpha$ & $28.4 \%$ \\
\hline
\end{tabular}
Importins a
GFP
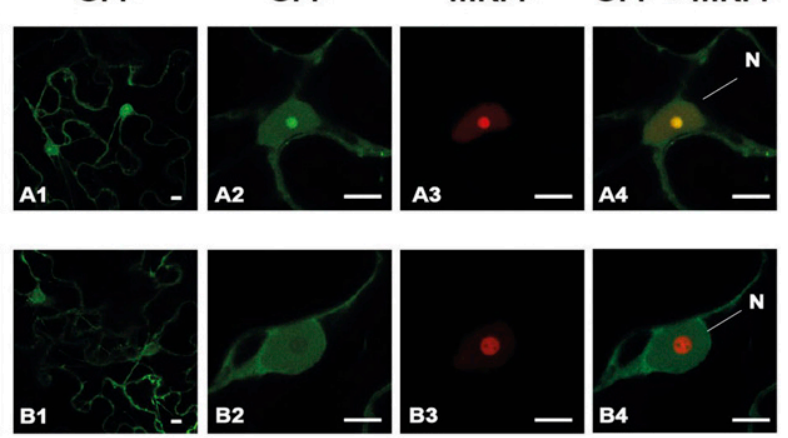

B3

B4 
compartmentalization-based regulation could rely just on the removal of part of $\mathrm{p} 37$ molecules from the cytoplasm to maintain the required protein amounts in this cellular compartment, in which PLPV replication cycle takes place, with the nucleolus functioning as a kind of $\mathrm{p} 37$ garbage disposal or even more actively contributing to p37 turnover. Regarding the latter, it is interesting that a proteasome-independent pathway for protein degradation has been reported in the nucleolus of animal cells (Tao et al. 2013), and the existence of a similar pathway in plant cells cannot be completely ruled out. Finally, the presence of p37 in the nucleolus could be related to an unknown function of the protein aimed to manipulate host nucleolar processes for virus's own benefit, such as, for instance, RNA silencing or ribosome biogenesis. Neither can the recruitment by $\mathrm{p} 37$ of some nucleolar components that might be essential for the PLPV biological cycle be excluded. In this connection, one of the few plant viral proteins for which a biological significance of its nucleolar localization has been advanced is that encoded by the ORF3 of an umbravirus (Groundnut rosette virus), a type of plant RNA virus that does not produce a CP and that also belongs to family Tombusviridae. The umbravirus ORF3-encoded product is involved in virus long-distance movement and has been proposed to hijack and relocalize fibrillarin from the nucleolus to the cytoplasm to participate in formation of viral RNPs. These RNPs protect viral RNAs and move through the phloem, determining the ability of the umbravirus to cause systemic infection (Kim et al. 2007). Interactions of some additional plant virus proteins (or RNAs) with fibrillarin alone or in combination with other nucleolar components have been reported, although their precise role during viral infectious cycle is mostly unclear (Jiang et al. 2010; Rajamäki and Valkonen 2009; Semashko et al. 2012; Shaw et al. 2014; Zheng et al. 2015). More investigation is being carried out to gain further insights into the precise biological meaning of the nucleolar localization of PLPV p37.

\section{MATERIALS AND METHODS}

\section{Plant material.}

$N$. benthamiana plants were grown from seeds in the greenhouse, under a 16 -h photoperiod and, respectively, 24 and $20^{\circ} \mathrm{C}$ day and night temperatures.

\section{DNA constructs.}

For PLPV inoculation, a pMOG800-based binary construct containing an infectious cDNA flanked by the Cauliflower

A

RNAi vector(s)

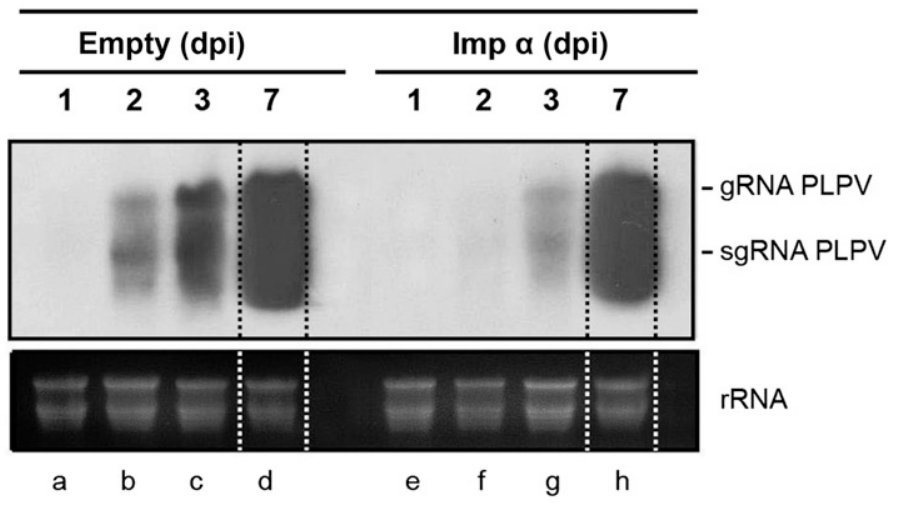

B
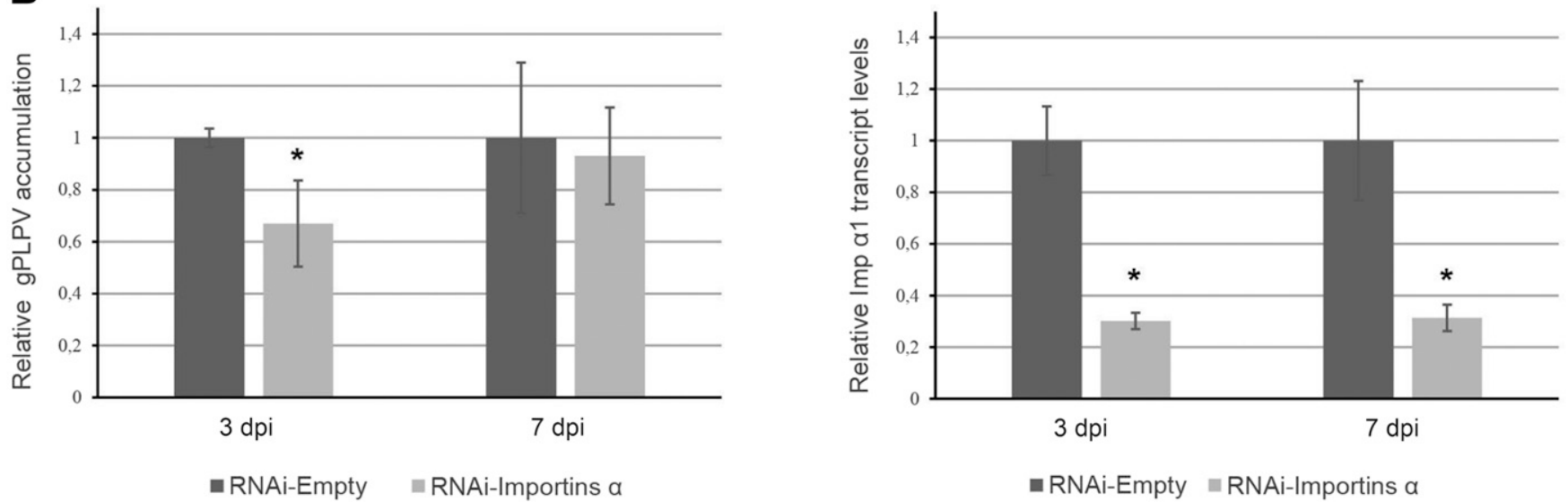

Fig. 5. Importin alpha depletion negatively affects in vivo Pelargonium line pattern virus (PLPV) accumulation. Nicotiana benthamiana leaves were agroinfiltrated with an RNA interference (RNAi) empty construct (mock control) or with a mixture of RNAi constructs to direct silencing of all importins alpha. At 5 days after infiltration, the same leaves were agroinoculated with a full-length cDNA clone of PLPV. Leaf samples were harvested at different days after virus inoculation (dpi). A, Northern blot analysis for PLPV detection in samples collected at 1, 2, 3, and 7 dpi from either mock controls (lanes a to d) or importin alpha-silenced leaves (lanes e to $\mathrm{h}$ ). The positions of the genomic ( $\mathrm{g}$ ) and subgenomic (sg) RNAs of PLPV are indicated at the right. Note that the virus was barely detectable at $1 \mathrm{dpi}$ in either case because of its low accumulation levels. Ethidium bromide staining of ribosomal RNA (rRNA) is shown below the blots as a loading control. Discontinuous lines indicate lanes that were not contiguous in the original gel. B, Reverse transcription-quantitative polymerase chain reaction to estimate relative PLPV accumulation (left panel) and relative levels of importin $\alpha 1$ transcripts (right panel) at 3 and 7 dpi. Bars depict standard deviations from three independent biological replicates. 
mosaic virus (CaMV) $35 \mathrm{~S}$ promoter and the terminator sequence of the Solanum tuberosum proteinase inhibitor II gene (PoPit) was used (Castaño et al. 2009).

For protein subcellular localization assays, a pMOG800based binary construct containing an expression cassette with the p37 gene, either unfused or fused in frame to the $5^{\prime}$ end of the GFP gene and flanked by the CaMV 35S promoter and the PoPit, has been described previously (Pérez-Cañamás and Hernández 2015). Selected regions of the p37 gene were PCR amplified with KAPA HiFi DNA polymerase (Kapa Biosystems) and suitable oligonucleotide primers to generate, following standard cloning procedures, similar pMOG800based constructs for expression of truncated versions of p37 fused to the GFP. Binary constructs for expression of fibrillarin fused to mRFP (used as nucleolar marker) or of the tombusvirus p19 (used for VSR function in some experiments), have been described elsewhere (Kim et al. 2007; Martínez-Turiño and Hernández 2009).

For BiFC assays, pROK2-sYFPN and pROK2-sYFPC-based plasmids directing expression of the p37 fused to the $\mathrm{N}$ - and C-terminal halves of the sYFP (aa 1 to 154 and 155 to 238, respectively) have been reported previously (Pérez-Cañamás and Hernández 2015). Similar pROK2-based constructs were generated for representative members of the importin alpha family. Specifically, sequences from the five importins alpha depicted in Figure 3A (representative of subclades Ia, Ib, and Ic and clades II and III, respectively) were retrieved from the Sol Genomics Network database, to design specific oligonucleotide primers that were used to amplify the corresponding full-length genes through RT-PCR, using the SuperScript III one-step RT-PCR system (Thermo Fisher Scientific) and total RNA extracts from $N$. benthamiana as templates. The primers included appropriate restriction sites to facilitate cloning of the amplified cDNA into pROK2-sYFPN and pROK2-sYFPC plasmids.

For coimmunoprecipitation assays, the importins alpha representatives of subclade Ia and clade III were PCR amplified from the corresponding BiFC constructs using KAPA HiFi PCR kit (Kapa Biosystems) and specific oligonucleotide primers were derived from the $5^{\prime}$ and $3^{\prime}$ gene termini. The reverse primers contained $5^{\prime}$-extra nucleotides encoding six His to fuse a His tag to the C-terminus of the gene products. In addition, forward and reverse primers harbored proper restriction sites to help cloning of the amplified genes into the pMOG800 vector under the control of CaMV $35 \mathrm{~S}$ promoter and PoPit terminator.

For RNAi assays, cDNA fragments were RT-PCR amplified from conserved regions of the importin alpha genes belonging to each phylogenetic clade or subclade (Ia, Ib, Ic, II, and III). Five cDNAs were generated using specific oligonucleotides bearing proper restriction sites at their $5^{\prime}$ end, which expedited their insertion into pHANNIBAL vector (Wesley et al. 2001). After digestion with the corresponding restriction enzymes, each DNA fragment was inserted in sense and antisense orientation flanking, respectively, the pyruvate dehydrogenase kinase intron present in pHANNIBAL vector. The resulting hairpin expression cassettes, which included a CaMV $35 \mathrm{~S}$ promoter and an A. tumefaciens octopine synthase gene terminator, were cut out by NotI digestion and were inserted into the unique NotI site of binary plasmid pCLEAN-G181 (Thole et al. 2007). The empty pHANNIBAL Not I cassette was also inserted into pCLEAN-G181 to produce a control plasmid pChpEMPTY.

All constructs were routinely sequenced with an ABI PRISM DNA sequencer 377 (Perkin-Elmer) to corroborate the validity of the selected recombinant plasmids. The primers used to generate the distinct recombinant constructs are listed in Supplementary Table S1.
Agrobacterium-mediated transient gene expression and virus inoculation.

Binary plasmid constructs were transformed into A. tumefaciens $\mathrm{C} 58 \mathrm{C} 1 \mathrm{CH} 32$ by the freeze-thaw shock method. Cultures of $A$. tumefaciens harboring the different Ti plasmids were infiltrated at an optical density at $660 \mathrm{~nm}\left(\mathrm{OD}_{660}\right)$ of 0.5 on the abaxial side of $N$. benthamiana leaves (5 weeks old), using a $20 \mathrm{ml}$ needleless syringe. When coinfiltrating distinct bacterial cultures, equal amounts of such cultures were mixed before infiltration (final $\mathrm{OD}_{660}$ of the mixed culture of 0.5 ). In the case of RNAi experiments, leaves were first infiltrated with importin alpha hairpin constructs (individually or combined) or the empty control construct and, 5 dai, the same leaves were agroinfiltrated with a pMOG-derived construct for expression of either GFP-tagged or untagged p 37 or for PLPV inoculation $\left(\mathrm{OD}_{660}=10^{-4}\right)$. The infiltrated plants were kept under greenhouse conditions and leaf samples were taken at distinct times after infiltration.

\section{Confocal microcopy.}

In BiFC and subcellular localization assays, GFP, mRFP, or reconstituted sYFP fluorophores of tagged proteins were monitored in epidermal cells of $N$. benthamiana-infiltrated tissue at $72 \mathrm{~h}$ postinfiltration, using a Leica TCS SL confocal microscope with an HCX PL APO $\times 40 / 1.25$ to 0.75 oil CS objective. GFP and sYFP fluorescence was recorded by excitation with $488 \mathrm{~nm}$ argon laser line with emission being collected through a band-pass filter from 505 to $550 \mathrm{~nm}$. In the case of mRFP, excitation was performed by means of a 543-nm green neon laser line and fluorescence emission was collected at 610 to $630 \mathrm{~nm}$.

\section{RNA extraction and Northern blot analysis.}

Total RNA preparations from $N$. benthamiana leaves were obtained by phenol extraction and lithium precipitation (Verwoerd et al. 1989). For Northern blot analysis, $4 \mu \mathrm{g}$ of total RNA was denatured by glyoxal-dimethyl sulfoxide treatment, was electrophoresed in $1 \%$ agarose gels, and was blotted to nylon membranes (Hybond N+; GE Healthcare). After UVcrosslinking, membranes were incubated at $70^{\circ} \mathrm{C}$, in the presence of $50 \%$ formamide, with a ${ }^{32} \mathrm{P}$-radioactive RNA probe for detection of PLPV RNAs. Such probe was generated by in-vitro transcription of a pBluescript $\mathrm{KS}(+)$-based construct containing the PLPV p37 gene (nucleotides 2,621 to 3,637 of the PLPV genome). After hybridization, membranes were washed at room temperature three times $(10 \mathrm{~min}$ each) in $2 \times \mathrm{SSC}(1 \times \mathrm{SSC}$ is $0.15 \mathrm{M} \mathrm{NaCl}$ plus $0.015 \mathrm{M}$ sodium citrate) plus $0.1 \%$ sodium dodecyl sulfate (SDS) and once at $55^{\circ} \mathrm{C}$ in $0.1 \times \mathrm{SSC}$ plus $0.1 \%$ SDS.

\section{Semiquantitative and RT-qPCR.}

Total RNA preparations with a RNA integrity number (Agilent) $\geq 7$ were treated with Turbo DNase (ThermoFisher). Assessment of downregulation of importin alpha gene expression in RNAi assays through semiquantitative RT-PCR was performed as follows. One microgram of treated total RNA for each sample was subjected to RT-PCR amplification with SuperScript III one-step RT-PCR system and a pair of specific primers that yielded a cDNA embracing a region of the importin alpha gene different from that cloned into the corresponding hairpin construct. The number of cycles for PCR amplification ranged from 20 to 30 and simultaneous amplification of an actin gene fragment was performed as internal control. RTqPCR was employed in some RNAi assays to compare viral titers and to confirm silencing of importin alpha. To this end, total RNA preparations, treated as indicated above, were reverse transcribed (1 $\mu \mathrm{g}$ per reaction) with PrimeScript RT 
reagent kit (Perfect Real Time; Takara), using either an oligodT primer (to generate cDNAs for subsequent PCR amplification of protein phosphatase 2A [PP2A] gene, employed as internal control, and importin alpha 1 gene) or, since PLPV RNAs lack a poly(A) tail at the $3^{\prime}$ end, a combination of an oligo-dT primer and a PLPV specific primer (to generate cDNAs for subsequent PCR amplification of PP2A gene and of a virus genome fragment, respectively). Design of primers for PCR was performed with Primer Express 2.0 software (Applied Biosystems), using the following criteria: melting temperature ranging from 50 to $60^{\circ} \mathrm{C}$, PCR amplicon lengths of 100 to $200 \mathrm{bp}$, length of primer sequences of 19 to 25 nucleotides, and guanine-cytosine content of 40 to $60 \%$. Master mix for qPCR was prepared with $5 \times$ PyroTaq EvaGreen qPCR Mix Plus (rhodamine X) (Cultek Molecular Bioline). Three biological replicates (with three technical replicates each) were performed for every type of sample. The PCR reactions were run and analyzed using the ABI PRISM 7700 Sequence detection system (Applied Biosystems Inc., Life Technologies Corp.) and evaluation of the relative expression level of each gene was carried out with the relative expression software tool REST designed by Qiagen.

\section{Subcellular fractionation and Western blot analysis.}

Subcellular fractionation of the leaf extracts was carried out as described previously for Solanaceae spp. (Sikorskaite et al. 2013). Briefly, $5 \mathrm{~g}$ of leaf material was ground with liquid nitrogen and the resulting leaf powder was thoroughly mixed with 5 volumes of NIB buffer (10 mM MES-KOH, pH 5.4, $10 \mathrm{mM} \mathrm{NaCl}, 10 \mathrm{mM} \mathrm{KCl}, 2.5 \mathrm{mM}$ EDTA, $250 \mathrm{mM}$ sucrose, $0.1 \mathrm{mM}$ spermine, $0.5 \mathrm{mM}$ spermidine, $1 \mathrm{mM}$ dithiothreitol [DTT]). The homogenate was filtered through three layers of Miracloth and the recovered solution (initial extract) was further clarified by the addition of Triton X-100 until a final concentration of $0.5 \%$, in order to accomplish lysis of contaminating organelles. After incubation for $20 \mathrm{~min}$ at $4{ }^{\circ} \mathrm{C}$, the homogenate was centrifuged at $1,000 \times g$ for $10 \mathrm{~min}$, the supernadant was removed (cytoplasmic fraction), and the pellet was gently resuspended in $10 \mathrm{ml}$ of NIB buffer. The crude preparation of nuclei was then loaded on a cushion formed by two layers of $2.5 \mathrm{M}$ sucrose and $60 \%$ Percoll, respectively. Following centrifugation at $1,000 \times g$ for $10 \mathrm{~min}$, the $60 \%$ Percoll layer that contained most of the nuclei was collected and was diluted with 5 volumes of NIB. After addition of Triton X-10 to a final concentration of $0.5 \%$, the sample was incubated for $10 \mathrm{~min}$ at $4^{\circ} \mathrm{C}$, centrifuged at $1,000 \times g$ for $10 \mathrm{~min}$, and the resulting pellet was resuspended in $5 \mathrm{ml}$ of NIB. The nuclei preparation was then overlaid on a $35 \%$ Percoll cushion, and after centrifugation at $1,000 \times g$ for $10 \mathrm{~min}$, the pellet was washed with NIB and, finally, resuspended in nuclei storage buffer NBS $(20 \%$ glycerol, $20 \mathrm{mM}$ HEPES KOH, pH 7.2, $5 \mathrm{mM} \mathrm{MgCl}_{2}, 1 \mathrm{mM}$ DTT) (nuclear fraction).

For Western blot analysis, aliquots of the obtained fractions were subjected to SDS-polyacrylamide gel electrophoresis, were transferred to polyvinylidene difluoride (PVDF) membranes (Roche), and were immunoblotted with antisera against p37 (AS-0094, DSMZ) at a 1:5,000 dilution, antibody against $\mathrm{H} 3$ (Agrisera) at a 1:6,000 dilution, or antibody against UDPglucose pyrophosphorylase (Agrisera) at a 1:3,000 dilution. Goat antirabbit horseradish peroxidase (HRP) conjugated (Agrisera) at a 1:10,000 dilution was used as secondary antibody, and immunoreactive bands were revealed with the chemiluminescence ECL Plus kit, following supplier recommendations (GE Healthcare). Signals were recorded by autoradiography and were quantified with the aid of a FujiFilm LAS3000 Imager.

\section{Coimmunoprecipitation assays.}

$N$. benthamiana leaves agroinfiltrated with proper binary constructs and collected at 3 to 5 dai were ground to a fine powder with liquid nitrogen and were homogenized in a $4-\mathrm{ml} / \mathrm{g}$ solution of IP buffer (50 mM Tris- $\mathrm{HCl}, \mathrm{pH} 7.4,100 \mathrm{mM} \mathrm{KCl}$, $100 \mathrm{mM} \mathrm{NaCl}, 2.5 \mathrm{mM} \mathrm{MgCl} 2,1 \mu \mathrm{g}$ of leupeptin per milliliter, $1 \mu \mathrm{g}$ of aprotonin per milliliter, $25 \mathrm{mM}$ phenylmethylsulfonyl fluoride, and 1 tablet of complete proteinase inhibitor cocktail [Roche Life Science]). Cell debris were removed by centrifugation at $12,000 \times g$ for $15 \mathrm{~min}$ at $4^{\circ} \mathrm{C}$ twice, and clarified lysates were incubated with $4 \mu \mathrm{g}$ of His-probe antibody per milliliter (H3, Santa Cruz Biotechnology) for $1 \mathrm{~h}$ at $4^{\circ} \mathrm{C}$ and then with $100 \mu \mathrm{l}$ of protein A per milliliter of $\mathrm{G}$ agarose beads (Roche Life Science) for $2 \mathrm{~h}$, with mild rotation. Beads were recovered by centrifugation at $500 \times g$ and were washed six times with IP buffer for $10 \mathrm{~min}$ at $4^{\circ} \mathrm{C}$. Proteins were eluted of $2 \times$ protein loading buffer (1.25 M Tris, pH 6.8, $10 \%$ SDS, $80 \%$ glycerol, $10 \% \beta$-mercaptoethanol, and $0.02 \%$ bromophenol blue), after heating at $95^{\circ} \mathrm{C}$ for $3 \mathrm{~min}$. Western blot analysis of protein inputs and immunoprecipitates for detection of $\mathrm{p} 37$ was performed as indicated above. His-tagged importins were detected similarly, using the mouse monoclonal His-probe antibody $\mathrm{H} 3$ at 1:5,000 dilution, as primary antibody, and sheep antimouse immunoglobulin G HRP conjugated (GE Healthcare) at 1:10,000 dilution, as secondary antibody.

\section{Phylogenetic and sequence analyses.}

The sequences for $N$. benthamiana importin alpha proteins were retrieved from the Sol Genomics Network database. The Molecular Evolutionary Genetics Analysis (MEGA7) software was used for aligning sequences, using the ClustalW algorithm, and preparing the tree (Kumar et al. 2016). Bootstrap values were calculated from 1,000 replicates of the tree. GenBank and Sol Genomics Network accession numbers are indicated on the phylodendrogram.

\section{ACKNOWLEDGMENTS}

We thank C. Mares for technical assistance and P. Fajardo for help in generation of some constructs.

\section{LITERATURE CITED}

Alexander, M. M., and Cilia, M. 2016. A molecular tug-of-war: Global plant proteome changes during viral infection. Curr. Plant Biol. 5:13-24.

Bachan, S., and Dinesh-Kumar, S. P. 2012. Tobacco rattle virus (TRV)based virus-induced gene silencing. Methods Mol. Biol. 894:83-92.

Boisvert, F.-M., van Koningsbruggen, S., Navascués, J., and Lamond, A. I. 2007. The multifunctional nucleolus. Nat. Rev. Mol. Cell Biol. 8:574-585.

Bouia, A., Kholti, A., Saghi, M., and Cornelis, P. 2001. In-frame fusion of a His-Cys motif into the Pseudomonas aeruginosa outer membrane OprI lipoprotein results in increased metal binding capacity by Escherichia coli. Res. Microbiol. 152:799-804.

Brothers, S. P., Janovick, J. A., and Conn, P. M. 2003. Unexpected effects of epitope and chimeric tags on gonadotropin-releasing hormone receptors: Implications for understanding the molecular etiology of hypogonadotropic hypogonadism. J. Clin. Endocrinol. Metab. 88:6107-6112.

Carmo-Fonseca, M., Mendes-Soares, L., and Campos, I. 2000. To be or not to be in the nucleolus. Nat. Cell Biol. 2:E107-E112.

Castaño, A., and Hernández, C. 2005. Complete nucleotide sequence and genome organization of Pelargonium line pattern virus and its relationship with the family Tombusviridae. Arch. Virol. 150:949-965.

Castaño, A., Ruiz, L., and Hernández, C. 2009. Insights into the translational regulation of biologically active open reading frames of Pelargonium line pattern virus. Virology 386:417-426.

Drissi, R., Dubois, M. L., and Boisvert, F. M. 2013. Proteomics methods for subcellular proteome analysis. FEBS J. 280:5626-5634.

Emmott, E., and Hiscox, J. A. 2009. Nucleolar targeting: The hub of the matter. EMBO Rep. 10:231-238.

Görner, W., Durchschlag, E., Martínez-Pastor, M. T., Estruch, F., Ammerer, G., Hamilton, B., Ruis, H., and Schüller, C. 1998. Nuclear localization of 
the $\mathrm{C} 2 \mathrm{H} 2$ zinc finger protein Msn2p is regulated by stress and protein kinase A activity. Genes Dev. 12:586-597.

Henke, R. M., Dastidar, R. G., Shah, A., Cadinu, D., Yao, X., Hooda, J., and Zhang, L. 2011. Hypoxia elicits broad and systematic changes in protein subcellular localization. Am. J. Physiol. Cell Physiol. 301:C913-C928.

Hiscox, J. A. 2007. RNA viruses: Hijacking the dynamic nucleolus. Nat. Rev. Microbiol. 5:119-127.

Jiang, Y., Li, Z., and Nagy, P. D. 2010. Nucleolin/Nsr1p binds to the $3^{\prime}$ noncoding region of the tombusvirus RNA and inhibits replication. Virology 396:10-20.

Kanneganti, T. D., Bai, X., Tsai, C. W., Win, J., Meulia, T., Goodin, M., Kamoun, S., and Hogenhout, S. A. 2007. A functional genetic assay for nuclear trafficking in plants. Plant J. 50:149-158.

Kim, S. H., Macfarlane, S., Kalinina, N. O., Rakitina, D. V., Ryabov, E. V., Gillespie, T., Haupt, S., Brown, J. W. S., and Taliansky, M. 2007. Interaction of a plant virus-encoded protein with the major nucleolar protein fibrillarin is required for systemic virus infection. Proc. Natl. Acad. Sci. U.S.A. 104:11115-11120.

König, R., Stertz, S., Zhou, Y., Inoue, A., Hoffmann, H. H., Bhattacharyya, S., Alamares, J. G., Tscherne, D. M., Ortigoza, M. B., Liang, Y., Gao, Q., Andrews, S. E., Bandyopadhyay, S., De Jesus, P., Tu, B. P., Pache, L., Shih, C., Orth, A., Bonamy, G., Miraglia, L., Ideker, T., García-Sastre, A., Young, J. A., Palese, P., Shaw, M. L., and Chanda, S. K. 2010. Human host factors required for influenza virus replication. Nature 463:813-817.

Kumar, S., Stecher, G., and Tamura, K. 2016. MEGA7: Molecular evolutionary genetics analysis version 7.0 for bigger datasets. Mol. Biol. Evol. 33: 1870-1874.

Ledent, P., Duez, C., Vanhove, M., Lejeune, A., Fonzé, E., Charlier, P., Rhazi-Filali, F., Thamm, I., Guillaume, G., Samyn, B., Devreese, B., Van Beeumen, J., Lamotte-Brasseur, J., and Frère, J. M. 1997. Unexpected influence of a C-terminal-fused His-tag on the processing of an enzyme and on the kinetic and folding parameters. FEBS Lett. 413:194-196.

Lukhovitskaya, N. I., Cowan, G. H., Vetukuri, R. R., Tilsner, J., Torrance, L., and Savenkov, E. I. 2015. Importin- $\alpha$-mediated nucleolar localization of potato mop-top virus TRIPLE GENE BLOCK1 (TGB1) protein facilitates virus systemic movement, whereas TGB1 self-interaction is required for cell-to-cell movement in Nicotiana benthamiana. Plant Physiol. 167:738-752.

Martin, R. M., Ter-Avetisyan, G., Herce, H. D., Ludwig, A. K., LättigTünnemann, G., and Cardoso, M. C. 2015. Principles of protein targeting to the nucleolus. Nucleus 6:314-325.

Martínez-Turiño, S., and Hernández, C. 2009. Inhibition of RNA silencing by the coat protein of Pelargonium flower break virus: Distinctions from closely related suppressors. J. Gen. Virol. 90:519-525.

McPherson, A. J., Lange, A., Doetsch, P. W., and Corbett, A. H. 2015 Nuclear-cytoplasmic transport. In: eLS. John Wiley \& Sons, Ltd., Chichester, U.K.

Melen, K., Fagerlund, R., Franke, J., Kohler, M., Kinnunen, L., and Julkunen, I. 2003. Importin alpha nuclear localization signal binding sites for STAT1, STAT2, and influenza A virus nucleoprotein. J. Biol. Chem. 278:28193-28200.

Noirot, E., Der, C., Lherminier, J., Robert, F., Moricova, P., Kiêu, K., Leborgne-Castel, N., Simon-Plas, F., and Bouhidel, K. 2014. Dynamic changes in the subcellular distribution of the tobacco ROS-producing enzyme RBOHD in response to the oomycete elicitor cryptogein. J. Exp. Bot. 65:5011-5022.

O’Neill, R. E., Jaskunas, R., Blobel, G., Palese, P., and Moroianu, J. 1995. Nuclear import of influenza virus RNA can be mediated by viral nucleoprotein and transport factors required for protein import. J. Biol. Chem. 270:22701-22704

Olson, M. O. J., and Dundr, M. 2015. Nucleolus: Structure and function. In: eLS. J. Wiley \& sons, Ltd., Chichester, U.K. DOI:

Pérez-Cañamás, M., Blanco-Pérez, M., Forment, J., and Hernández, C. 2017. Nicotiana benthamiana plants asymptomatically infected by Pelargonium line pattern virus show unusually high accumulation of viral small RNAs that is neither associated with DCL induction nor RDR6 activity. Virology 501:136-146.
Pérez-Cañamás, M., and Hernández, C. 2015. Key importance of small RNA binding for the activity of a glycine-tryptophan (GW) motifcontaining viral suppressor of RNA silencing. J. Biol. Chem. 290: 3106-3120.

Rajamäki, M. L., and Valkonen, J. P. 2009. Control of nuclear and nucleolar localization of nuclear inclusion protein a of picorna-like Potato virus $A$ in Nicotiana species. Plant Cell 21:2485-2502.

Rao, A. L. 2006. Genome packaging by spherical plant RNA viruses. Annu. Rev. Phytopathol. 44:61-87.

Salvetti, A., and Greco, A. 2014. Viruses and the nucleolus: The fatal attraction. Biochim. Biophys. Acta 1842:840-847.

Scheets, K., Jordan, R., White, K. A., and Hernández, C. 2015. Pelarspovirus, a proposed new genus in the family Tombusviridae. Arch. Virol. 160: 2385-2393.

Scott, M. S., Boisvert, F. M., McDowall, M. D., Lamond, A. I., and Barton, G. J. 2010. Characterization and prediction of protein nucleolar localization sequences. Nucleic Acids Res. 38:7388-7399.

Semashko, M. A., González, I., Shaw, J., Leonova, O. G., Popenko, V. I., Taliansky, M. E., Canto, T., and Kalinina, N. O. 2012. The extreme $\mathrm{N}$-terminal domain of a hordeivirus TGB1 movement protein mediates its localization to the nucleolus and interaction with fibrillarin Biochimie 94:1180-1188.

Shaw, J., Love, A. J., Makarova, S. S., Kalinina, N. O., Harrison, B. D., and Taliansky, M. E. 2014. Coilin, the signature protein of Cajal bodies, differentially modulates the interactions of plants with viruses in widely different taxa. Nucleus 5:85-94.

Shaw, P. J. 2015. Nucleolus. In: eLS. J. Wiley \& sons, Ltd., Chichester, U.K. Sikorskaite, S., Rajamäki, M. L, Baniulis, D., Stanys, V., and Valkonen, J. P. 2013. Protocol: Optimised methodology for isolation of nuclei from leaves of species in the Solanaceae and Rosaceae families. Plant Methods 9:31.

Sit, T. L., and Lommel, S. A. 2015. Tombusviridae. In: eLS. J. Wiley and Sons, Ltd., Chichester, U.K.

Smith, H. M., Hicks, G. R., and Raikhel, N. V. 1997. Importin alpha from Arabidopsis thaliana is a nuclear import receptor that recognizes three classes of import signals. Plant Physiol. 114:411-417.

Taliansky, M. E., Brown, J. W. S., Rajamäki, M. L., Valkonen, J. P., and Kalinina, N. O. 2010. Involvement of the plant nucleolus in virus and viroid infections: Parallels with animal pathosystems. Adv. Virus Res. 77:119-158.

Tao, T., Shi, H., Guan, Y., Huang, D., Chen, Y., Lane, D. P., Chen, J., and Peng, J. 2013. Def defines a conserved nucleolar pathway that leads p53 to proteasome-independent degradation. Cell Res. 23: 620-634.

Thole, V., Worland, B., Snape, J. W., and Vain, P. 2007. The pCLEAN dual binary vector system for Agrobacterium-mediated plant transformation. Plant Physiol. 145:1211-1219.

Verwoerd, T. C., Dekker, B. M., and Hoekema, A. 1989. A small-scale procedure for the rapid isolation of plant RNAs. Nucleic Acids Res. 17: 2362.

Wesley, S. V., Helliwell, C. A., Smith, N. A., Wang, M. B., Rouse, D. T., Liu, Q., Gooding, P. S., Singh, S. P., Abbott, D., Stoutjesdijk, P. A., Robinson, S. P., Gleave, A. P., Green, A. G., and Waterhouse, P. M. 2001. Construct design for efficient, effective and high-throughput gene silencing in plants. Plant J. 27:581-590.

Zheng, L., Du, Z., Lin, C., Mao, Q., Wu, K., Wu, J., Wei, T., Wu, Z., and Xie, L. 2015. Rice stripe tenuivirus p2 may recruit or manipulate nucleolar functions through an interaction with fibrillarin to promote virus systemic movement. Mol. Plant Pathol. 16: 921-930

\section{AUTHOR-RECOMMENDED INTERNET RESOURCES}

Sol Genomics Network database: http://solgenomics.net

Sol Genomics Network Blast database: http://solgenomics.net/tools/blast/index.pl 